九州大学学術情報リポジトリ

Kyushu University Institutional Repository

\title{
A GIS-based Linear Programming Model for Optimizing Agricultural Land Levelling
}

Wang, Guoqiang

College of Water Sciences, Beijing Normal University

Xue, Baolin

Laboratory of Forest Ecosystem Management, Division of Forest Ecosphere Management, Department of Forest \& Forest Products Sciences, Graduate School of Bioresource and Bioenvironmental

Sciences, Kyushu University

Yu, Jingshan

College of Water Sciences, Beijing Normal University

Otsuki, Kyoichi

Laboratory of Forest Ecosystem Management, Division of Forest Ecosphere Management, Department of Forest \& Forest Products Sciences Faculty of Agriculture, Kyushu University

https://doi.org/10.5109/17814

出版情報: 九州大学大学院農学研究院紀要. 55 (1)，pp.131-135，2010-02-26. Faculty of Agriculture, Kyushu University

バージョン :

権利関係 : 


\title{
A GIS-based Linear Programming Model for Optimizing Agricultural Land Levelling
}

\author{
Guoqiang WANG ${ }^{1 *}$, Baolin $\mathrm{XUE}^{2}$, Jingshan $\mathrm{YU}^{1}$ \\ and Kyoichi OTSUKI
}

\author{
Laboratory of Forest Ecosystem Management, Division of Forest Ecosphere Management, \\ Department of Forest \& Forest Products Sciences Faculty of Agriculture, \\ Kyushu University, Fukuoka 811-2415, Japan \\ (Received November 2, 2009 and accepted November 19, 2009)
}

\begin{abstract}
Land levelling is an important process of the agricultural land consolidation projects. The land levelling process starts by determining the appropriate levels of the terrain and solves the earthwork allocation for the predetermined terrain levels. The recent attempt, reported in the literature, to find an optimal process is a GIS-based approach which solves the transportation problem by determing the designed terrain level and optimal hauling distances that result in the lowest hauling cost. In this study, the Vogel approximation method (VAM) was adopted in initializing the solution to the transportation problems, and the optimization of the solutions obtained by the VAM was examined using the modified distribution method (MODI). To verify the reliability of this combined method, a case study was carried out based on the proposed land levelling project at the Lixian District of Beijing, China. The results show that the optimal average hauling distance calculated from the proposed linear programming model is $79.53 \mathrm{~m}$ shorter than that estimated using the empirical method, and the unit cost calculated from the linear programming model is $33.4 \%$ lower than the experienced cost. The improvements in the optimization of the hauling distance show that the cost of the agricultural land levelling can be efficiently lowered if an appropriate linear programming model is used.
\end{abstract}

Keywords: GIS, land levelling, agriculture, transportation

\section{INTRODUCTION}

Land levelling is the construction work to level agricultural fields for land reclamation, improvement, rehabilitation, etc. It is one of the four major activities in the land consolidation. It normally costs about $40-70 \%$ of the total consolidation cost, which is associated with cutand-fill earthworks and hauling costs. Thus optimization of the land levelling process has been required to reduce the cost. Although there are quite a few researches for the optimization of cut-and-fill earthworks (Mayer and Stark, 1981; Nandgaonkar, 1981; Rapcsak, 1983), researchs on the optimization of hauling is very limited (Moreb and Bafail, 1994). Rapcsak (1983) used a linear programming model for the optimal land levelling, but his model did not include the hauling cost problem. The land levelling works for undulating sites mainly focus on site terracing works, and the average hauling distance is normally set to about 2/3 of site diameter (Liu and Wang, 2004). Recently, several researchers have noticed this problem and related land levelling with transportation solutions. Easa (1988) integrated the levelling stage with the earthwork allocation stage in his model and solved the transportation problem associated with each of these

${ }^{1}$ College of Water Sciences, Beijing Normal University, Xinjiekouwai Street 19, Beijing 100875, China

${ }^{2}$ Laboratory of Forest Ecosystem Management, Division of Forest Ecosphere Management, Department of Forest \& Forest Products Sciences, Graduate School of Bioresource and Bioenvironmental Sciences, Kyushu University, Fukuoka 8112415, Japan

* Corresponding author (E-mail: wangguoqiang_bnu@hotmail. com) levels to select the level with lowest hauling cost. Moreb and Bafail (1994) presented a linear programming model that combined land levelling and the associated transportation problems to optimize hauling cost. However, these attempts failed to calculate the hauling distance for the sites with complex landforms. This resulted in difficulties and uncertainties in the estimation of earthwork volume and the relevant hauling cost. In order to represent the uneven ground features, high-resolution DEMs (Digital Elevation Model) were used to provide terrain data to support the analysis of landform characteristics. The objective of this study is to integrate the linear programming model with GIS approach and apply the GIS based model in solving the optimal land levelling cost of agricultural land. The model was operated at several grid resolutions to show the correlation between the DEM resolution and the total land levelling cost of agricultural land.

\section{METHODS}

\section{Land leveling cost}

The land levelling cost depends on both the cutand-fill earthwork cost and hauling cost. In order to predict the earthwork volume of land levelling, it is necessary to know both cut-and-fill volume and hauling distance. The optimized distribution of cut and fill quantities was determined using the linear programming method of Moreb (1996), considering the optimal earthwork allocation and transportation problems in the levelling process. In this method, it was assumed that the unit hauling cost was linearly proportional to the hauling distance. The specific unit costs for earthwork activities including 
cut (excavation), fill (embankment), and hauling were defined based on the construction budget rate published by local government. The objective function that minimizes the land levelling cost $(F)$ was as follows:

$$
\begin{aligned}
\min F & =\sum_{i=1}^{m} C_{c}(i) X_{c}(i)+\sum_{j=1}^{n} C_{f}(j) X_{f}(j) \\
& +\sum_{i=1}^{m} \sum_{j=1}^{n} C_{h} D(i, j) X_{h}(i, j)
\end{aligned}
$$

subject to $\quad X_{c}(i) \geq 0, \quad X_{f}(j) \geq 0, \quad X_{h}(i, j) \geq 0$

$m \quad=$ number of the cut grids.

$n \quad=$ number of the fill grids.

$C_{c}(i)=$ cost of cutting one cubic unit of earth from grid $i$.

$C_{f}(j)=$ cost of filling one cubic unit of earth to grid $j$.

$C_{h} \quad=$ cost of hauling one cubic unit of earth at one unit distance.

$D(i, j)=$ distance between grid i and grid $j$.

$X_{c}(i) \quad=$ amount of earth cut from grid $i$.

$X_{f}(j) \quad=$ amount of earth filled to grid $j$.

$X_{h}(i, j)=$ amount of earth hauled from grid i to grid $j$.

In the model, the cut grids were distinguished from the fill grids using a designed terrain level. In most cases, the designed terrain level was calculated according to the principle of balanced the cut and fill volumes.

$$
\sum_{i=1}^{m} X_{c}(i)=\sum_{j=1}^{n} X_{f}(j)
$$

Once the designed terrain level is decided, the earthwork costs of cutting and filling can be treated as constants for a certain project site. Thus, the minimum land levelling cost can be derived by solving the optimal hauling cost (min $F^{\prime}$ ) from the linear programming model.

$$
\min F^{\prime}=\sum_{i=1}^{m} \sum_{j=1}^{n} C_{h} D(i, j) X_{h}(i, j)
$$

\section{Transportation problem}

In order to minimize the hauling cost, it is necessary to determine the optimal hauling distances between cut grids and fill grids. The transportation problem involved in the hauling can also be solved by linear programming model. Since the cost of hauling one cubic unit of earth at one unit distance is generally treated as a constant, the objective function of the linear programming model can be redefined to minimize the earthwork volume of hauling operation as:

$$
\min f=\sum_{i=1}^{m} \sum_{j=1}^{n} D(i, j) X_{h}(i, j)
$$

The transportation problem is generally solved by the following routines:

1) defining the objective function,

2) initializing the problem with any feasible solution by an optimization method and

3) examining the optimization suitability of the obtained solution.

Several methods can be used for finding the initial basic feasible solutions. There are several methods that can be used to generate the initial solution for the balanced transportation problem, such as northwest corner method, minimum cost method, row minimum method, column minimum method, etc. All these methods differ in the ways of starting the basic solutions; better starting solution can usually yield a smaller objective value.

In this paper, Vogel approximation method (VAM) was introduced for setting an initial solution to the transportation problems. VAM is not as simple as the northwest corner approach, but it facilitates a good initial solution, which is often the optimal solution. VAM tackles the problem of finding a good initial solution by taking into account the costs associated with each route alternative. VAM computes for each row and column the penalty faced if the second best route is selected instead of the least cost route (Imam et al., 2009). Table 1 shows the transportation simplex tableau for the earth hauling involved in land levelling. The cut grids $\left(\mathrm{A}_{\mathrm{i}}\right)$ and fill grids $\left(B_{j}\right)$ represent the supplies and demands in the transportation problem.

The optimization suitability of the solutions obtained by the VAM was tested using the Modified Distribution (MODI) method. The MODI method allows computing improvement indices quickly for each unused cell of the transportation tableau without drawing all the closed paths. The MODI method provides considerable time savings over other methods for solving transportation problems and an approach of finding the unused route with the largest negative improvement index. Once the largest index is identified, only one closed path should be traced. This path helps determine the maximum number of units that can be transported via the best unused route. In applying the MODI method, a value needs to be assigned to each row $\left(R_{1}, R_{2}, \ldots R_{m}\right)$ and for each column $\left(K_{1}, K_{2}\right.$,

Table 1. Transportation tableau for land levelling

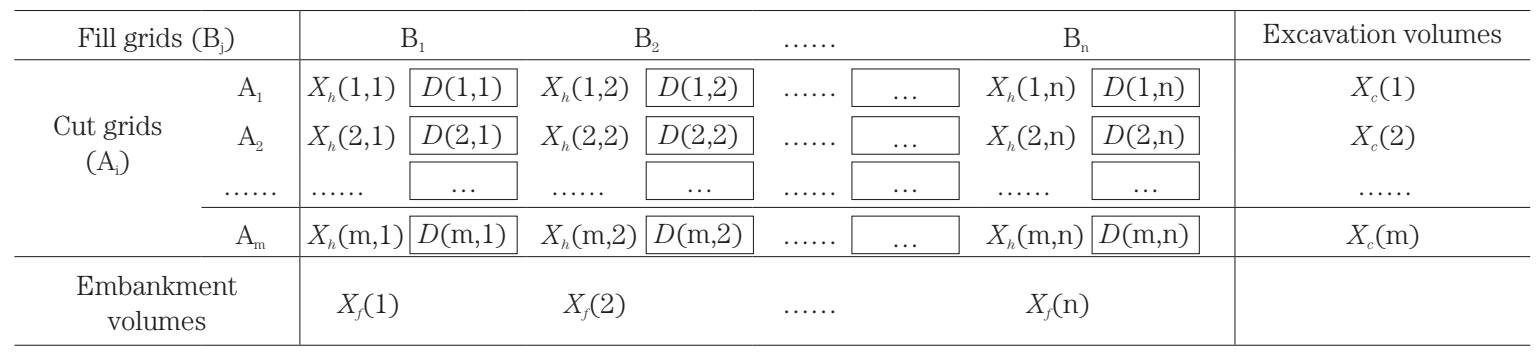


$\ldots K_{n}$ ) in the transportation tableau. The MODI method requires the following five steps:

1) To compute the values for each row and column, set

$$
R_{i}+K_{j}=C_{h} D(i, j) X_{h}(i, j)
$$

2) After all equations have been written, set $R_{1}$ to 0 .

3) Solve the system of equations for all $R$ and $K$ values.

4) Compute the improvement index for each unused cell by the formula improvement index $I$.

$$
I_{i, j}+C_{h} D(i, j) X_{h}(i, j)-R_{i}-K_{j}
$$

5) Select the largest negative index and proceed to solve the problem.

Using the integrated VAM and MODI methods, the allocation volume $X_{h}(i, j)$ and the optimal hauling distance $D(i, j)$ were determined for each cell. The optimal average hauling distance $\bar{D}^{*}$ was then calculated for the whole land levelling project as

$$
\bar{D}^{*}=\frac{\min f}{\sum_{i=1}^{m} X_{c}(i)}
$$

\section{DATA PROCESSING}

High-resolution DEMs generated using contour data were used to provide terrain data to support the analysis of landform characteristics. Digitized continuous contour lines were stored in a rectangular grid and tagged with elevation values, while new contours were obtained by an iterative dilation applied to the earlier contour lines that increased their surfaces on both sides, until they became contiguous. The limit between two adjoining surfaces was considered as the position of a new contour whose altitude was the value intermediate between the two altitude values of the given land surfaces. The new contour lines generated were added to the rectangular grid. This procedure was repeated until no new contour lines were obtained. The data processing and model operation were performed under the structure of ArcView GIS. The linear programming model was developed using Visual Basic and linked to ArcView GIS using Dynamic Data Exchange (DDE) method. A user friendly interface was also developed using the script language of ArcView GIS. In this study, the contour lines with the resolutions of 5, 10 and 20 meters were used to generate the DEM data respectively. The designed terrain level $H_{d}$ was then calculated according to the principle of balanced cutand-fill volumes using the generated DEM data. Once $H_{d}$ was determined, the cut grids and fill grids can be identified by comparing the local heights $H_{l}(k)$ $(\mathrm{k} \in[1, \mathrm{~m}+\mathrm{n}])$ with $H_{d}$. The cut volume $X_{c}(k)$ was calculated from:

$$
X_{c}(k)=\left(H_{l}(k)-H_{d}\right) \cdot l^{2} \quad \text { if } \quad H_{l}(k) \geq H_{d}
$$

where $l$ is the length of grid cell. The fill volume $X_{f}(k)$ was calculated from:

$$
X_{f}(k)=\left(H_{d}-H_{l}(k)\right) \cdot l^{2} \quad \text { if } \quad H_{l}(k)<H_{d}
$$

The hauling distances between the cut grids and fill grids are then determined from:

$$
D(i, j)=l \cdot \sqrt{\left(r_{i}-r_{j}\right)^{2}+\left(c_{i}-c_{j}\right)^{2}}
$$

$r_{i}=$ Row number of $i$ th cut grid.

$r_{j}=$ Row number of $j$ th fill grid .

$c_{i} \quad=$ Column number of $i$ th cut grid .

$c_{j}=$ Column number of $j$ th fill grid.

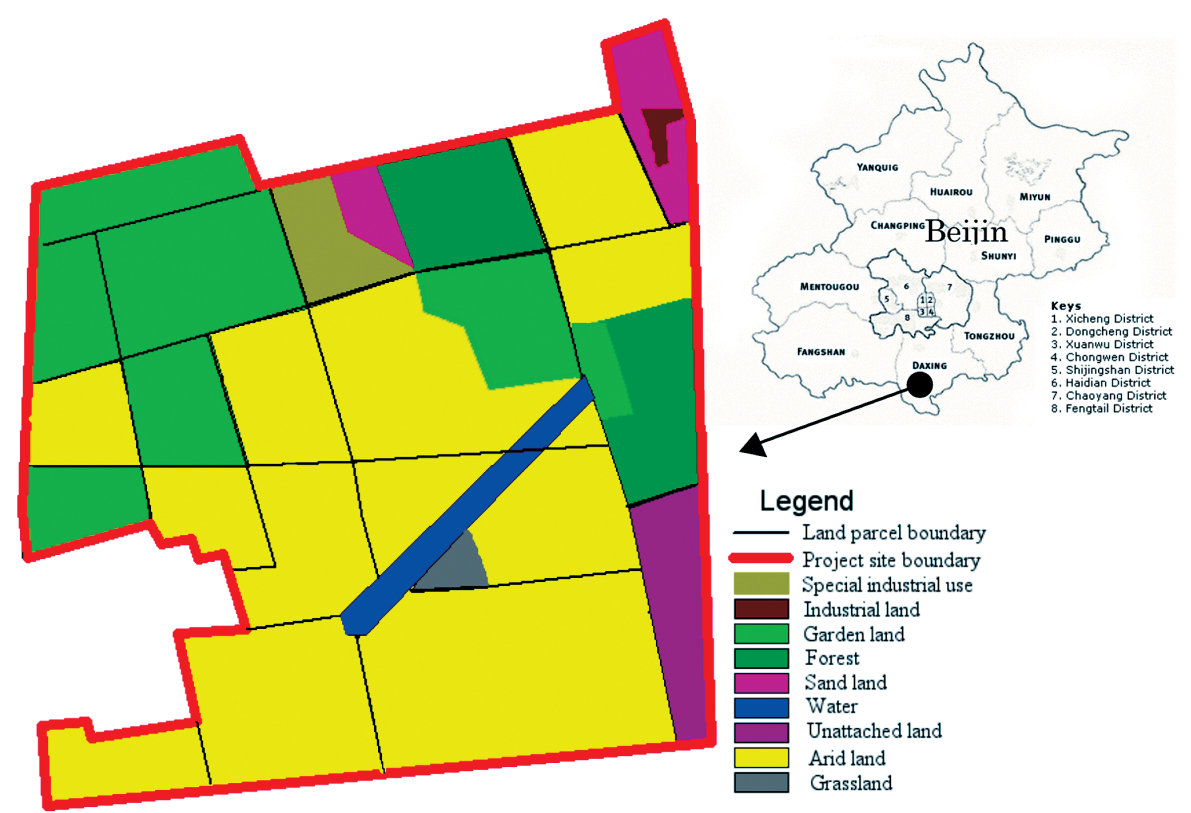

Fig. 1. Map of the project site 


\section{CASE STUDY}

In order to verify the accuracy and applicability of the proposed linear programming model, a case study was carried out based on a proposed land levelling project at Lixian District of Daxing Town, Beijing. The project site is located between $116^{\circ} 22^{\prime} 57^{\prime \prime} \mathrm{E}$ and $116^{\circ} 24^{\circ} 09^{\prime \prime} \mathrm{E}$ longitude and $39^{\circ} 33^{\prime} 45^{\prime \prime} \mathrm{N}$ and $39^{\circ} 34^{\prime} 40^{\prime \prime} \mathrm{N}$ latitude, on an alluvial plain of Yongding River with uneven landforms and elevations of about $22 \mathrm{~m}$ to $35 \mathrm{~m}$. The location and land use types of the project site is shown in Figure 1. According to the construction instruction, the land levelling should be done within the independent land parcels, and the typical land parcel size was $405 \mathrm{~m} \times 335 \mathrm{~m}$. With consideration of buffer zone, irrigation and mechanization requirements, the site was subdivided into 19 land parcels (as shown in Figure 1). The designed terrain level was determined based on the principles of balanced earthwork of cut-and-fill volumes within each land parcel. In this case study, performance of the linear programming model was validated based on the calculation on a land parcel, Parcel 7. According to the experienced calculation method of the hauling distance on farmland terracing, the normal hauling distance was about $2 / 3$ of the width of subject land parcel, that is, the usual hauling distance was estimated to be $223.33 \mathrm{~m}$, with direct unit cost of RMB15.79/ $\mathrm{m}^{3}$.

The optimal hauling costs calculated from the linear programming model were tightly related with the unit cost and hauling distance results. This study adopted the unit costs published in the 'Beijing Construction Budget Rate' (Sheet No. 1-45 and 1-49). It must be noted that Sheet No.1-49 specifies that when hauling distance exceeds $20 \mathrm{~m}$, an increase of $10 \mathrm{~m}$ of hauling distance will entail in an increase of RMB0.66/ $\mathrm{m}^{3}$ of direct cost. Grid resolutions of resolutions of $5 \times 5 \mathrm{~m}, 10 \times 10 \mathrm{~m}$ and $20 \times 20 \mathrm{~m}$ were used in calculating the optimal hauling distances respectively. The calculated transportation costs and optimal average hauling distances are presented in Table 2.

As shown in Table 2 , when the grid sizes are $10 \times 10 \mathrm{~m}$ and $5 \times 5 \mathrm{~m}$, the difference of optimal average hauling distances is only $1.42 \%$ and there is no different in term of unit costs, hence no significant effect on the direct cost is expected. However, when the grid size increases to $20 \times 20 \mathrm{~m}$, it will entail in $7.58 \%$ difference in term of optimal average hauling distance comparing to the case of $5 \times 5 \mathrm{~m}$ grid size, while the difference of direct cost is $6.28 \%$, hence significant effect on direct cost is expected. Based on the past experiences of land levelling works, the normal lengths of grid edge are between $10 \mathrm{~m}$ and $20 \mathrm{~m}$. The typical optimal average hauling distance is $143.80 \mathrm{~m}$, with direct unit cost of RMB10.51/ $\mathrm{m}^{3}$. The optimal average hauling distance calculated from the linear programming model is $79.53 \mathrm{~m}$ shorter than the distance estimated using the experienced method. The unit cost calculated from the linear programming model is 33.4\% lower than the experienced cost. Therefore, the hauling distance and unit cost results were validated to be appropriate by comparing to the experienced values.

\section{CONCLUSION}

This study applied the principle of linear programming model to solve the transportation problems involved in the agricultural land levelling. Vogel approximation method was used in generating the initial solution to the transportation problems, and the optimization suitability of the solutions obtained by the VAM is tested using the modified distribution method. The reliability of this combined linear programming model was then validated in the consequent case study. With digitalized topographic data, the accuracy of the simulated results have tight correlations with the input grid resolutions, which leads to a necessity of determining an appropriate grid resolution for calculating the optimal hauling cost. Normally, smaller grid sizes produce higher accuracy results. However, when the project site is subdivided into regular grid cells, the number of the grid cells is shown to be reversely proportional to grid size by power four. If the grid size reduces by half, the number of grid cells will increase by three times and the average iteration times of calculation will by 15 times. Based on the past experiences of actual land levelling works, the diameters of land parcels are normally in the range of $10-20 \mathrm{~m}$. Therefore, the grid size could be set at $10 \mathrm{~m}$, which will not only increase the accuracy of the calculation but will also facilitate the execution of earthworks.

This paper presents the preliminary results of research on hauling distance. Application of the present model on the case study site shows that calculation results are realistic. With further studies, the proposed linear programming model shall be applied in the similar analysis of the agricultural land levelling issues.

Table 2. Optimal average hauling distances and costs for different grid sizes

\begin{tabular}{ccccccc}
\hline \multirow{2}{*}{$\begin{array}{c}\text { Grid size } \\
(\mathrm{m} \times \mathrm{m})\end{array}$} & $\begin{array}{c}\text { Grid number } \\
(\text { row } \times \text { column })\end{array}$ & $\begin{array}{c}\text { Optimal average } \\
\text { hauling distance } \\
(\mathrm{m})\end{array}$ & \multicolumn{3}{c}{ Unit costs for transportation $\left(\mathrm{RMB} / \mathrm{m}^{3}\right)$} \\
\cline { 5 - 7 } & $17 \times 20$ & 131.04 & 9.85 & 0.69 & 0.00 & 9.16 \\
$20 \times 20$ & $33 \times 40$ & 143.80 & 10.51 & 0.74 & 0.00 & 9.77 \\
$10 \times 10$ & $67 \times 81$ & 141.78 & 10.51 & 0.74 & 0.00 & 9.77 \\
$5 \times 5$ & & Total & Machinery \\
cost
\end{tabular}

Note: Total cost includes labor cost, material cost and machinery cost. Rates are based on standard rate number 1-45 and 1-49 of the 'Beijing Construction Budget Rate'. 


\section{REFERENCES}

Moreb, A. A. and A. O. Bafail 1994. A linear programming model combining land levelling and transport problems. J. Opl. Res. Soc., 45(12): 1418-1424

Moreb, A. A. 1996. Linear programming model for finding optimal roadway grades that minimize earthwork cost. Eur. $J$. Opl. Res., 93: 148-154

Liu, C. S. and G. Q. Wang 2004. Model of economic transportation distance for land consolidation project. Transactions of the Chinese Society of Agricultural Engineering, 20: 273275 (in Chinese)
Mayer, R. and R. Stark 1981. Earthmoving logistics. J. Constr. Div., Proc. Am. Soc. Civil Eng. 107: 279-312

Easa, S. M. 1988. Selection of roadway grades that minimize earthwork cost using linear programming. Transp. Res. A., $\mathbf{2 2 A}(2): 121-136$

Nandgaonkar, S. 1981. Earth work transportation allocation. $J$ Constr. Div., Proc. Am. Soc. Civil Eng. 107: 373-392

Imam, T., G. Elsharawy, M. G. Iman 2009. Solving transportation problem using object oriented model. International Journal of Computer Science and Network Security, 9(2): 353-361

Rapcsak, T. 1983. A linear programming model for optimal levelling of an irrigation surface. Eur. J. Opl. Res., 13: 369-373 